\title{
Necrosis tisular local y trombocitopenia después de una intoxicación por mordedura de Bungarus multicinctus en una niña
}

\author{
Local tissue necrosis and thrombocytopenia following Bungarus multicinctus \\ envenomation in a child
}

\begin{abstract}
Dr. Ning Wang ${ }^{a, b}$, Dr. Xuedong Wu $u^{a, b}$, Máster en Ciencias Shanshan Zhang g,b, Máster en Ciencias Wei Shen ${ }^{a, b}$ y Máster en Ciencias Na Lia,b
\end{abstract}

\begin{abstract}
RESUMEN
La intoxicación por mordedura de serpiente es un problema de salud pública global. En la población pediátrica, la intoxicación por mordedura de serpiente presenta características diferentes que en los pacientes adultos. La Bungarus multicinctus es una especie de elápido sumamente venenoso. Las presentaciones clínicas documentadas después de la intoxicación por mordedura de Bungarus multicinctus son reacciones locales mínimas, insuficiencia respiratoria, dolor generalizado e hiponatremia potencialmente mortal. Presentamos el caso de una intoxicación por mordedura de Bungarus multicinctus en una niña con manifestaciones clínicas atípicas, incluidas necrosis tisular grave y trombocitopenia con coagulopatía.

Palabras clave: Bungarus multicinctus, necrosis, trombocitopenia, trastorno de coagulación de la sangre, niño.
\end{abstract}

http: / / dx.doi.org/10.5546/ aap.2021.e80

Texto completo en inglés:

http: / / dx.doi.org/10.5546/ aap.2021.eng.e80

Cómo citar: Wang N, Wu X, Zhang S, Shen W, Li N. Necrosis tisular local y trombocitopenia después de una intoxicación por mordedura de Bungarus multicinctus en una niña. Arch Argent Pediatr 2021;119(1):e80-e83.

a. Departamento de Cirugía Pediátrica, Primer Hospital Afiliado, Universidad de Dali, China.

b. Centro de Medicina Clínica Pediátrica, sucursal de Dali, provincia de Yunnan, China.

Correspondencia: Dr. Ning Wang:wn20153240@163.com

Financiamiento: Los autores recibieron el apoyo financiero del Departamento de Educación de la provincia de Yunnan (2019J0780).

Conflicto de intereses: Ninguno que declarar.

Recibido: 19-7-2020

Aceptado: 28-9-2020

\section{INTRODUCCIÓN}

Cada año, se producen alrededor de 5 millones de mordeduras de serpiente en todo el mundo. ${ }^{1}$ La Bungarus multicinctus es una especie de elápido sumamente venenoso, que se encuentra ampliamente en el sur de China. Las mordeduras de Bungarus multicinctus representan aproximadamente el 7,5\% de todos los registros anuales de mordedura de serpiente en China, ${ }^{2}$ con una tasa de mortalidad informada de alrededor del $7 \%$ al $50 \%$. $^{2,3}$ Las presentaciones clínicas documentadas causadas por la intoxicación por mordedura de Bungarus multicinctus incluyen reacciones locales mínimas, ${ }^{3}$ insuficiencia respiratoria, dolor generalizado ${ }^{2}$ e hiponatremia potencialmente mortal. ${ }^{4,5}$ Presentamos un caso infrecuente de intoxicación por mordedura de Bungarus multicinctus en una niña con necrosis tisular grave y trombocitopenia con coagulopatía.

\section{A PROPÓSITO DE UN CASO}

Una niña de 7 años que vivía en un área montañosa del sur de China sufrió una mordedura de una serpiente con muchas bandas en el dedo índice derecho mientras trataba de sacar una pelota de plástico de un agujero. Su padre presenció el evento y mantuvo a la serpiente alejada. La llevaron de inmediato al departamento de cirugía pediátrica, pero no recibió ningún tratamiento específico. Tardaron tres horas en trasladarla a nuestra institución. Según lo que describió el padre con respecto al proceso, el cirujano le mostró una imagen de la Bungarus multicinctus para que diera su testimonio. El padre la identificó rápidamente como la serpiente que había mordido a su hija.

La niña estaba consciente y refirió tener dolor en la mano derecha. Sus signos vitales eran los siguientes: frecuencia cardíaca de 100 latidos por minuto, presión arterial sistólica de $98 \mathrm{mmHg}$ y presión arterial diastólica de $70 \mathrm{mmHg}$, frecuencia respiratoria de 28 , saturación de oxígeno del $98 \%$ 
y temperatura corporal de $36,8^{\circ} \mathrm{C}$. Al momento del ingreso, tenía marcas de colmillos en el dedo índice derecho. La sensibilidad superficial y el llenado capilar en el lugar de la mordedura eran normales. Por lo demás, no presentaba erupción cutánea, enrojecimiento ni hinchazón. La niña fue hospitalizada; los resultados positivos de las pruebas de laboratorio incluyeron un recuento de leucocitos de $21,75 \times 10^{9} / 1$ y una concentración de potasio sérico de $3,1 \mathrm{mmol} / 1$. El tiempo de protrombina (TP) y la razón internacional normalizada (RIN) eran de 11,7 segundos y 1,02 segundos, respectivamente (Tabla 1). Las funciones hepática y renal eran normales. Se recetó un tratamiento específico con antídoto para las mordeduras de víbora, antitoxina tetánica y cefalexina en el lapso de una hora desde el inicio de la hospitalización. En los siguientes 30 minutos, se realizó una limpieza quirúrgica. Se mantuvo abierta la herida y se la enjuagó bien con solución salina. Se volvieron a revisar el hemograma completo y la función de coagulación en las primeras 24 horas después de la limpieza quirúrgica. Al segundo día, en la exploración física se observó enrojecimiento, hinchazón y eritema en el lugar de la mordedura. El recuento de plaquetas disminuyó de $369 \times 10^{9} / 1$ a $32 \times 10^{9} / 1$, con una prolongación del tiempo de protrombina $y$ una mayor concentración de dímero D (DD) y del producto de la degradación de la fibrina (PDF) (Tabla 1). Se sumó la difenhidramina a la cefalexina. Al tercer día, en la mano afectada, los dedos estaban pálidos, con sensibilidad superficial reducida e hinchazón progresiva que se extendía desde el lugar de la mordedura hacia el antebrazo. La extremidad superior derecha era sensible a la palpación (Figura 1A). Se realizó una descompresión abierta del túnel carpiano y del compartimiento fascial del antebrazo en forma urgente. Veinticuatro horas después de los procedimientos invasivos, la sensibilidad superficial y el llenado capilar mejoraron. Sin embargo, los recuentos de plaquetas siguieron

Figura 1. Mano derecha después de la mordedura de una Bungarus multicinctus

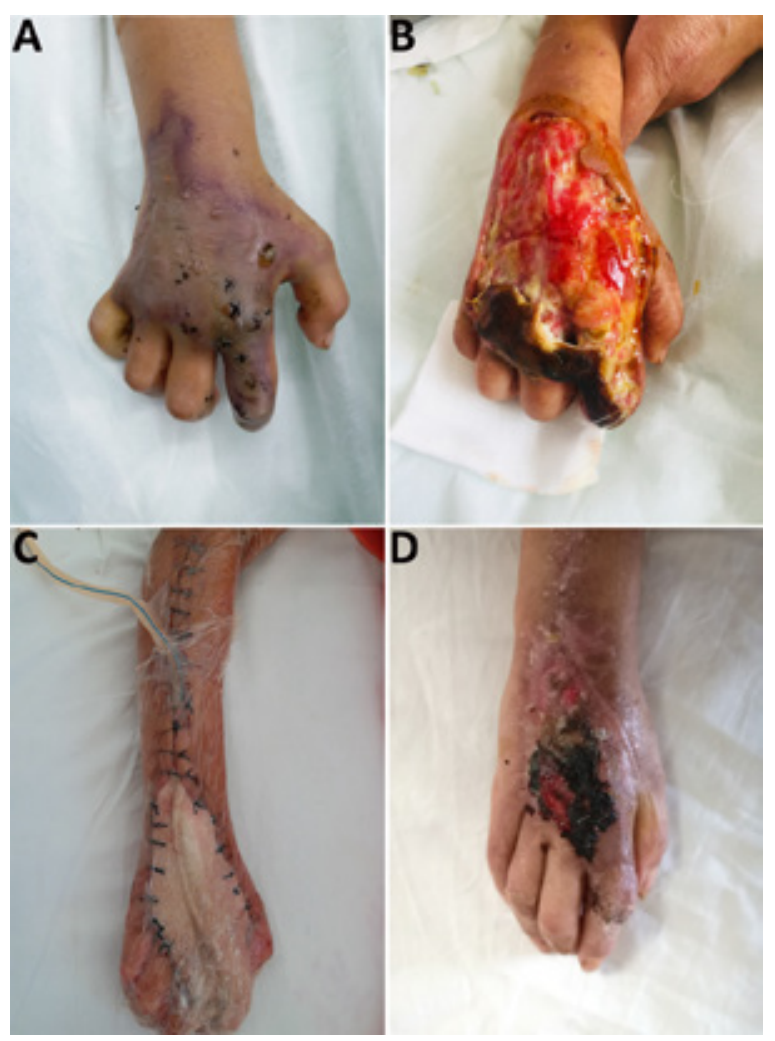

A: 3 días después de la intoxicación por mordedura de serpiente, tumefacción progresiva de la mano.

B: 5 días después de la intoxicación por mordedura de serpiente, necrosis de la piel de espesor total que se extiende hacia la muñeca. C: 17 días después de la intoxicación por mordedura de serpiente, drenaje de sellado al vacío (DSV) continuo en la mano derecha.

D: 60 días después de la intoxicación por mordedura de serpiente, cicatrización de la herida de la mano derecha.

TABla 1. Evolución del recuento de plaquetas y de la función de coagulación

\begin{tabular}{|c|c|c|c|c|c|c|}
\hline Valor de la prueba & Día 1 & Día 2 & Día 3 & Día 4 & Día 5 & Día 74 \\
\hline Recuento de plaquetas $\left(\times 10^{9} / 1\right)$ & 369 & 32 & 3 & 64 & 68 & 490 \\
\hline $\mathrm{TP}(\mathrm{s})$ & 11,7 & 20,9 & 44,8 & 11,5 & 12,4 & 12,2 \\
\hline TP-RIN (s) & 1,02 & 1,88 & 4,23 & 1 & 0,93 & 1,06 \\
\hline TTPa (s) & 23,6 & 33,4 & 32,2 & 22,7 & 25,1 & 23,1 \\
\hline TT (s) & 18,7 & 19,1 & 18,3 & 14,8 & 15 & 19,2 \\
\hline $\mathrm{DD}(\mu \mathrm{g} / \mathrm{ml})$ & 0,77 & 2,73 & 3,17 & 1,24 & 0,35 & 0,28 \\
\hline $\mathrm{PDF}^{*}(\mu \mathrm{g} / \mathrm{ml})$ & 3,6 & 16,6 & 12,27 & 5,08 & 3,2 & 2,5 \\
\hline
\end{tabular}

TP: tiempo de protrombina; TP-RIN: tiempo de protrombina/razón internacional normalizada; TTPa: tiempo de tromboplastina parcial activado; TT: tiempo de trombina; DD: dímero D; PDF: producto de la degradación de la fibrina; *: el valor normal del PDF es inferior a $5 \mu \mathrm{g} / \mathrm{ml}$. 
disminuyendo. El recuento de plaquetas más bajo fue de $3 \times 10^{9} / 1$, junto con una prolongación del tiempo de protrombina de 44,8 s (Tabla 1). La paciente requirió una transfusión de plaquetas y de crioprecipitado alogénico. No presentó episodios de hemorragia. Al quinto día, comenzó a tener necrosis completa de la piel en el lugar de la mordedura que se extendía hacia la muñeca. La pérdida de piel de espesor total alcanzó alrededor del $1 \%$ de la superficie corporal (Figura 1B). La paciente tenía movimiento limitado en el dedo índice derecho debido al daño significativo en la articulación metacarpofalángica. Los resultados de los cultivos microbianos de los exudados de la herida fueron negativos. La disminución progresiva del recuento de plaquetas se detuvo. Los parámetros de coagulación volvieron a valores normales. A los 17 días, se realizó una limpieza de la herida y se aplicó un drenaje de sellado al vacío (DSV) continuo (Figura 1C).

El día 39, se intentó reparar el defecto cutáneo de la mano derecha con un colgajo cruzado de piel del brazo. El día 75, las heridas estaban cicatrizando correctamente. En el hemograma completo, se observó recuento de leucocitos de $6,5 \times 10^{9} / 1$ y recuento de plaquetas de $490 \times 10^{9} / 1$ (Tabla 1). En una consulta de seguimiento 60 días después del alta, la función normal del dedo índice derecho aún dependía de ejercicios de rehabilitación específicos para una recuperación a largo plazo (Figura 1D).

\section{DISCUSIÓN}

Los síntomas neuromusculares son complicaciones conocidas destacadas de la intoxicación por mordedura de B. multicinctus. ${ }^{6}$ En la bibliografía existente, también se documentan reacciones locales leves. ${ }^{2}$ Las reacciones locales graves y la trombocitopenia significativa con coagulopatía observadas en nuestro caso no se habían informado previamente.

El grado de las lesiones producidas por intoxicación por mordedura de serpientes es relevante según la categoría de veneno de la serpiente. Los venenos de la $B$. multicinctus que han sido debidamente estudiados son la $\alpha-, \beta-$ y $\gamma$-bungarotoxina. La $\alpha$-bungarotoxina destruye la unión de la acetilcolina y los receptores acetilcolínicos; la $\beta$ - y la $\gamma$-bungarotoxina inhiben la liberación de la acetilcolina de las terminaciones nerviosas. La reducción de la despolarización en la membrana postsináptica produce bloqueo neuromuscular. Los síntomas frecuentes incluyen ptosis, oftalmoplejía, midriasis, dolor faríngeo, parálisis del paladar, parálisis de las extremidades e incluso parálisis de los músculos respiratorios, que es el principal factor que causa insuficiencia respiratoria en los pacientes. . $^{3,8}$ Sin embargo, los síntomas relevantes de nuestro caso fueron necrosis tisular grave y trombocitopenia, en lugar de síntomas neuromusculares. Esto indica que la víctima sufrió un tipo diferente de destrucción por el veneno. De hecho, se han identificado 136 proteínas en la Bungarus multicinctus. Aproximadamente el 5,9\% de las proteínas son venenosas. Además de las 17 familias tóxicas descubiertas previamente, se hallaron nuevas familias de proteínas en el veneno de la B. multicinctus, entre otras, fosfolipasas A2 (FLA2), metaloproteinasa, hialuronidasa y factor de crecimiento endotelial vascular. ${ }^{9}$ Aún se desconocen las reacciones biológicas y los efectos clínicos que causan.

La destrucción tisular relacionada con el veneno de serpiente puede producir efectos fisiopatológicos, sociales y psicológicos a largo plazo en las víctimas. ${ }^{10,11}$ Entre los cambios patológicos complejos, el daño inducido por el veneno en las células y las matrices extracelulares (MEC) es un factor importante para la destrucción tisular. Los homólogos de las FLA2 son las principales micotoxinas que destruyen la integridad de la membrana plasmática. ${ }^{12}$ Las metaloproteinasas del veneno de serpiente (MPVS) pueden degradar las MEC. ${ }^{9}$ Tanto las FLA2 como las MPVS se encuentran en el veneno de la B. multicinctus. Estas podrían ser responsables de la necrosis tisular grave observada en nuestro caso.

La coagulopatía y la hemorragia son efectos potenciales en las víctimas tras una intoxicación por mordedura de serpiente. La desfibrinación y la anticoagulación son los dos patrones principales en la coagulopatía inducida por el veneno de serpiente. ${ }^{13}$ La coagulopatía por desfibrinación se manifiesta como una prolongación del TP/TP-RIN y TTPa con aumento del PDF. La coagulopatía por anticoagulación se manifiesta como prolongación del TP/TP-RIN y del TTPa con PDF bajo o ausente. La prolongación del TP/TP-RIN y del TTPa con aumento del PDF que se observó en nuestro caso se ajustaron a las características de la coagulopatía por desfibrinación.

Las plaquetas tienen una función importante en los procesos hemostáticos humanos. ${ }^{13} \mathrm{Se}$ producen dos efectos dramáticos, como la inhibición o promoción de la actividad plaquetaria, en la función plaquetaria después 
de la intoxicación por mordedura de serpiente. La promoción excesiva de la actividad plaquetaria aumenta el consumo de plaquetas disponibles, lo que lleva a una menor cantidad de plaquetas circulantes. También aumenta el riesgo de hemorragia. Dos componentes del veneno, las FLA2 y la $\alpha$-fibrinogenasa, promueven la actividad plaquetaria. La actividad plaquetaria inducida por las FLA2 podría ser responsable de la trombocitopenia que ocurrió en nuestro caso.

A diferencia de las coagulopatías frecuentes, el desarrollo rápido y la resolución espontánea son típicos de la coagulopatía relacionada con la mordedura de serpiente. Sin embargo, la velocidad del desarrollo y de la resolución de la coagulopatía es sumamente variable. El tiempo entre la mordedura y la coagulopatía puede ser inferior a 15 minutos en el caso de algunos elápidos australianos, mientras que la resolución completa podría tardar varias horas o días. ${ }^{13}$ Por el contrario, en nuestro caso, la coagulopatía inicial se presentó 24 horas después de la mordedura, pero la coagulopatía grave con trombocitopenia ocurrió a las 48 horas. La resolución completa de la coagulopatía se produjo 72 horas después de la mordedura. La aparición de la coagulopatía marcada se dio relativamente tarde, mientras que el consumo de los factores de coagulación comenzó con la activación temprana del sistema de coagulación provocada por la intoxicación por mordedura de serpiente.

Cabe destacar que identificamos a la $B$. multicinctus mediante un testimonio en lugar de su captura. Es posible que la evolución clínica atípica de la mordedura de Bungarus se deba a que se trataba de otra especie.

En este artículo, presentamos un caso aislado de necrosis tisular local y coagulopatía con trombocitopenia por intoxicación por mordedura de $B$. multicinctus. Las reacciones regionales fueron peores que en los informes previos. El veneno de la $B$. multicinctus contiene varias toxinas que podrían contribuir tanto a estos efectos locales como a la coagulopatía con trombocitopenia. La administración de un antídoto para la B. multicinctus es la base del tratamiento si la víctima sufrió una intoxicación por mordedura de B. multicinctus. Si el antídoto específico no está disponible, la corrección de la coagulopatía y la instauración de una intervención quirúrgica son medidas de apoyo para reducir las complicaciones relacionadas con el veneno.

\section{REFERENCIAS}

1. Gutiérrez JM, Calvete JJ, Habib AG, Harrison RA, et al. Snakebite envenoming. Nat Rev Dis Primers. 2017; 3:17079.

2. Mao YC, Liu PY, Chiang LC, Liao SC, et al. Bungarus multicinctus snakebite in Taiwan. Am J Trop Med Hyg. 2017; 96(6):1497-1504.

3. Pe T, Myint T, Htut A, Myint AA, Aung NN. Envenoming by Chinese krait (Bungarus multicinctus) and banded krait (B. fasciatus) in Myanmar. Trans R Soc Trop Med Hyg. 1997; 91(6):686-8.

4. Höjer J, Tran Hung H, Warrell D. Life-threatening hyponatremia after krait bite envenoming - a new syndrome. Clin Toxicol (Phila). 2010; 48(9):956-7.

5. Trinh KX, KhacQL, Trinh LX, WarrellDA. Hyponatraemia, rhabdomyolysis, alterations in blood pressure and persistent mydriasis in patients envenomed by Malayan kraits (Bungarus candidus) in southern Viet Nam. Toxicon. 2010; 56(6):1070-5.

6. Shan LL, Gao JF, Zhang YX, Shen SS, et al. Proteomic characterization and comparison of venoms from two elapid snakes (Bungarus multicinctus and Naja atra) from China. J Proteomics. 2016; 138:83-94.

7. Hung HT, Höjer J, Du NT. Clinical features of 60 consecutive ICU-treated patients envenomed by Bungarus multicinctus. Southeast Asian J Trop Med Public Health. 2009; 40(3):518-24.

8. ChanJC, Cockram CS, Buckley T, Young K, et al. Evenoming by Bungarus multicinctus (many-banded krait) in Hong Kong. J Trop Med Hyg. 1995; 98(6):457-60.

9. Ziganshin RH, Kovalchuk SI, Arapidi GP, Starkov VG, et al. Quantitative proteomic analysis of Vietnamese krait venoms: Neurotoxins are the major components in Bungarus multicinctus and phospholipases A2 in Bungarus fasciatus. Toxicon. 2015; 107(Pt B):197-209.

10. Edgerton MT, Koepplinger ME. Management of Snakebites in the Upper Extremity. J Hand Surg Am. 2019; 44(2):137-42.

11. Gutierrez JM, Rucavado A, Escalante T, Herrera C, et al. Unresolved issues in the understanding of the pathogenesis of local tissue damage induced by snake venoms. Toxicon. 2018; 148:123-31.

12. Fernandez CA, Borges RJ, Lomonte B, Montes MR. A structure-based proposal for a comprehensive myotoxic mechanism of phospholipase A2-like proteins from viperid snake venoms. Biochim Biophys Acta. 2014; 1844(12):226576.

13. White J. Snake venoms and coagulopathy. Toxicon. 2005; 45(8):951-67. 